\title{
Strathpeffer Spa: Dr William Bruce and polymyalgia rheumatica
}

\author{
ALASTAIR G. MOWAT \\ From the Department of Rheumatology, Nuffield Orthopaedic Centre, Oxford
}

SUMMARY The first description of polymyalgia rheumatica is attributed to Dr William Bruce working in Strathpeffer Spa, Scotland, in 1888. His career, the history of the spa, and the original article are briefly described.

\begin{abstract}
'Near here is a valley, birchwoods, heather and a streamNo country, no place was ever for a moment so delightful to my soul.'1
\end{abstract}

A Scottish spa may seem a contradiction in terms, but Strathpeffer, 24 miles north-west of Inverness and protected in its wooded valley from the prevailing winds by $3500 \mathrm{ft}(1070 \mathrm{~m})$ Ben Wyvis is 'set like a jewel' mid the splendors of the North.'2

The first medical reference to the springs is in a paper by Dr Donald Munro to the Royal Society in $1772,^{3}$ and 5 years later the Rev. Colin Mackenzie, minister of the parish and factor of the Cromartie estate, had detailed reports drawn up. While the waters became known locally, it was Dr Thomas Morrison of Elswick, Aberdeenshire, who, having

Accepted for publication 28 November 1980

Correspondence to Dr A. G. Mowat, Department of Rheumatology, Nuffield Orthopaedic Centre, Headington, Oxford OX3 7LD. succeeded in finding alleviation for his arthritis at Strathpeffer when he had failed at other British spas, decided to retire in the valley and devote his energies to extending the spa's benefits to a wider public. One result was the first, wooden pump room in 1819 . Its remoteness as the only true spa north of Harrogate hindered its development, and Fox ${ }^{2}$ wrote, 'old men still alive remember the month's journey from London with the Laird's coach'. However, the Highland Railway pushing steadily northward reached the Strath in 1885 , and it was then possible to travel overnight from London, arriving midmorning, without leaving one's compartment.

From then until the first World War the spa enjoyed great popularity boosted by the visits of European royalty, so that a number of imposing hotels were built and the facilities were extended several times. Today, although many of the buildings remain, including the pump house and a delightful

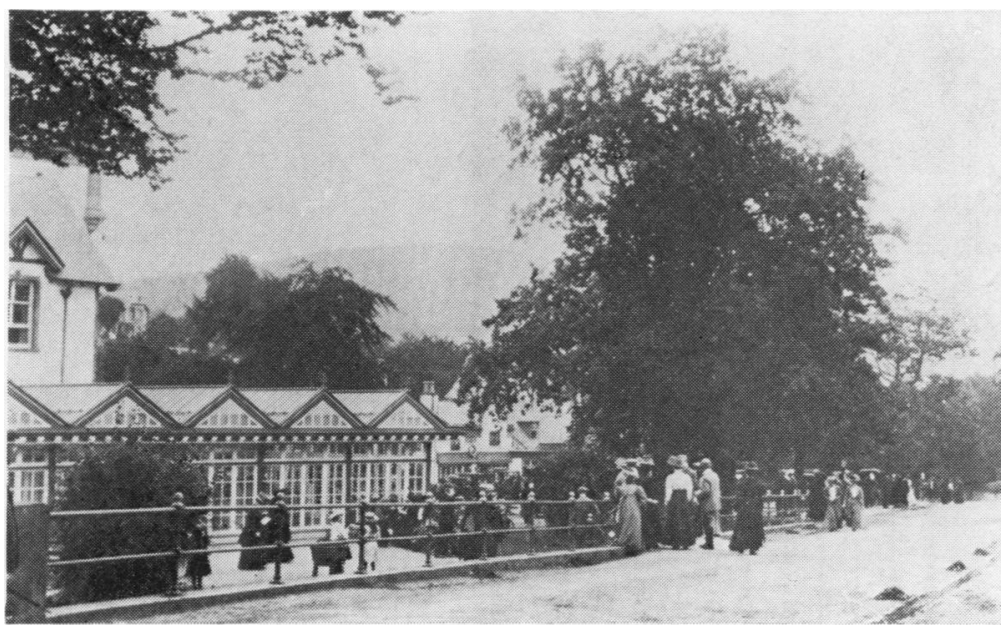

Fig. 1 Patrons waiting to enter the now demolished bathhouse. 
group of shops of late Victorian construction, one of which has been a pharmacy since it was built, the main bathhouse in the square has gone (Figs. 1-4). The spring waters, 4 sulphurous and 1 chalybeate (iron), continue to flow. Unlike most spa waters they are cold, and although hot baths were used the Scottish cold douche had a special reputation. The coldness perhaps accounted for the greater palatability of these waters compared with many, despite their high mineral content. Patrons were expected to consume their first glass of water at least 1 hour before breakfast, and a piper walked the town in full blow at 7.00 am to ensure they were awake in sufficient time. To match the mud of other centres, peat baths were added in the 1890 s.
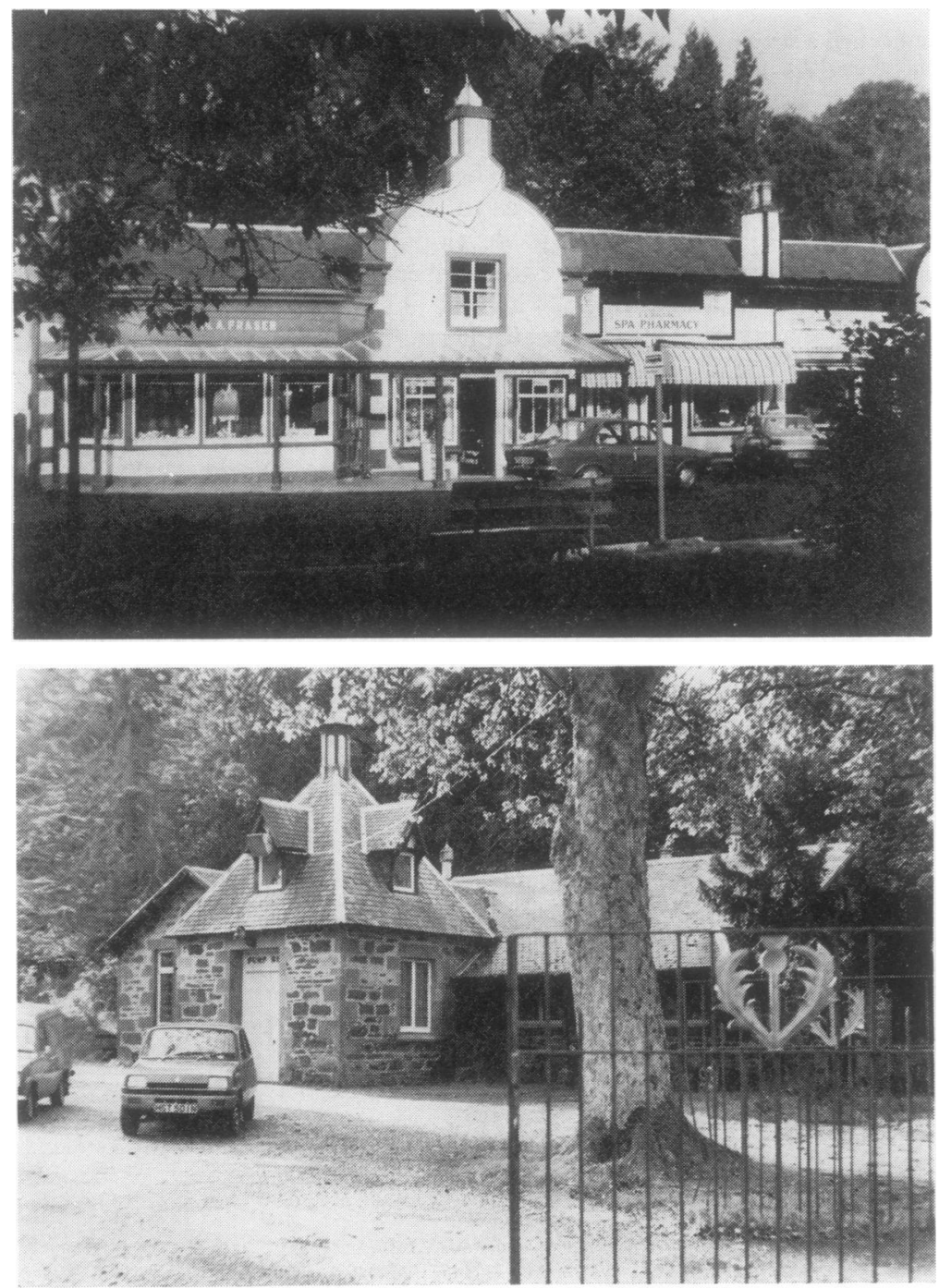

Fig. 2 The shops, seen in the background of Fig. 1, which continue to trade.

Fig. 3 The pump room dating from the turn of the century. 


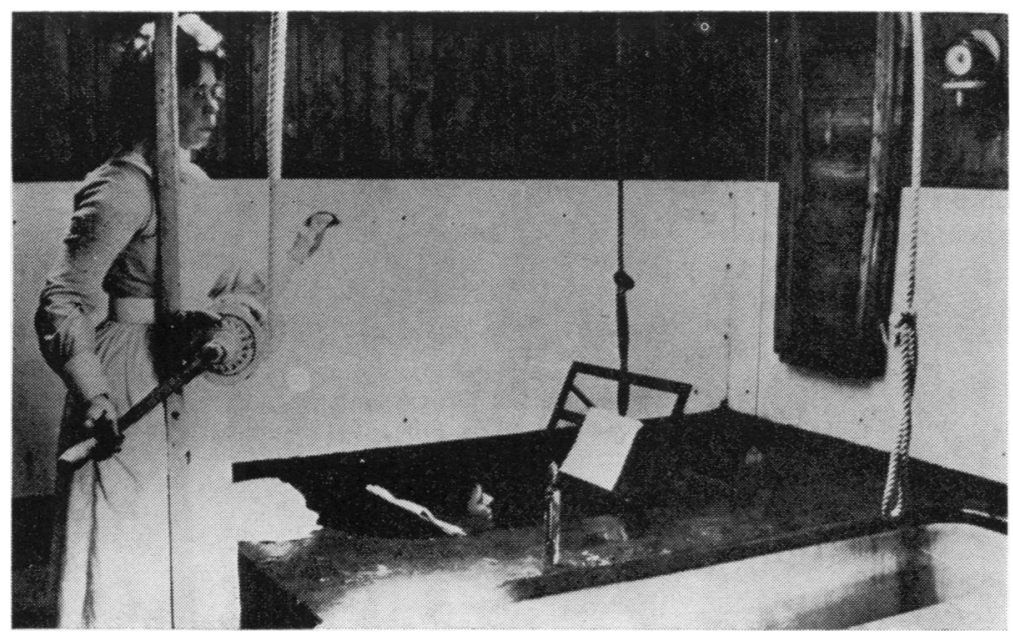

Fig. 4 Treatment in progress.

Dingwall, where he opened the Ross Memorial Hospital in 1873. In 1889 he became chief medical officer of health for Ross and Cromarty.

From 1870 until shortly before his death at his house, The Castle, Dingwall, in October 1920 he was closely associated with Strathpeffer Spa 4 miles $\left(6 \frac{1}{2} \mathrm{~km}\right)$ away, working with the Countess of Cromartie to develop the facilities. The esteem in which he was held locally is shown by the length of his obituary in the Ross-shire Journal, ${ }^{4}$ while Fox ${ }^{5}$ wrote of his late colleague "he had a hardy physique, disdainful of fatigue. . . . His mental energy and power of work were not less remarkable and he had the great gift of tenacious memory. Such men not only seize opportunities, but make them....' He had a national reputation from his frequent communications, from his being the first direct Scottish representative to the General Medical Council following the Medical Act of 1886 , a position he held for 20 years, and from his selection by Queen Victoria to accompany the Duke of Coburg to Egypt as private physician.

\section{Polymyalgia rheumatica}

Although much concerned with rheumatic problems Bruce is remembered today for his paper in 1888 on senile rheumatic gout, which is considered the first recognisable account of polymyalgia rheumatica. ${ }^{6}$ He wrote, 'There is, perhaps, no disease as to which professional opinion differs more than as to rheumatic gout. This diversity of views is unfortunate, as it affects the kind of treatment and mode of life of the patient, and it disturbs the lay mind and gives occasion for remarks as to the uncertainties of medicine. One school leans more to the gouty origin of the disease and another to the rheumatic. The victim himself naturally prefers to believe he is suffering from rheumatism, and becomes thereby free from many of the restrictions he has got to submit to if dubbed gouty'. His paper shows that he clearly understood acute gout and its relationship to the uric acid findings of Garrod and acute rheumatism, for which he, unlike others, favoured an infective aetiology. He also recognised rheumatoid arthritis 'of the common (?) definite, type' as a distinct clinical entity predominating in women and claimed one or two undoubted cures at Strathpeffer after successive visits, but felt that "in this, as in so many other complaints, cheerfulness and hope are the best of all medicine'.

His five cases of acute senile rheumatic gout were all males aged from 60 to 74 years. The name reflects partly the language of the time but partly Bruce's belief that the cause might be another metabolic abnormality closely related to gout: 'nature works in a continuous manner without leaps or breaks and instead of diseases being sharply defined as in our vocabularies, they probably run the one into the other, so as to leave no distinct boundaries or divisions'. In all 5 cases there was a sudden onset of severe pain and stiffness after getting wet or chilled, which in one was so disabling he could not turn himself in bed. In 4 the involvement of the shoulder girdle was prominent, while in 2 there was clearly some modest peripheral joint swelling. The time course varied from 12 months in one to 2 years or a little more in the others. The complete recovery, albeit with appropriate Strathpeffer therapy, the age of the patients, and the absence of a family history 
impressed him, since recovery from rheumatic disease other than gout at any age was rare and virtually unknown in the elderly. He concludes in a diffident manner, which was only to be expected since it took more than 60 years ${ }^{7}$ for the disease to be recognised again, ' $I$ feel that $I$ have been scarcely able to prove my contention that these acute senile cases belong to a different category ... remarkable in its severity and complete curability even at a very advanced time of life. ...'

I am grateful to Mrs Spark, The Pharmacy, Strathpeffer, for permission to reproduce Figs. 2 and 4.

\section{References}

1 Stevenson $\mathbf{R}$ L. Description of Strathpeffer. Letters. August 1880.

2 Fox R F. Strathpeffer Spa. London: Lewis, 1889.

3 Munro D. An account of the sulphureous mineral waters of Castle-Leod and Fairburn, in the County of Ross; and of the salt purging water of Pitkeathly, in the County of Perth, in Scotland. Philos Trans $R$ Soc Lond 1772; 62: 15-32.

4 Obituary W. Bruce. Ross-Shire Journal. 29 October 1920, Dingwall.

5 Fox R F. Br Med J 1920; ii: 804.

- Bruce W. Senile rheumatic gout. Br Med J 1888; ii: 811-3.

? Mowat A G. Generalised rheumatism: polymyalgia rheumatica and its differential diagnosis. Clin Rheum Dis $1979 ; 5$ : 775-95. 